\title{
Celso Furtado: um pensador social brasileiro*
}

\author{
Celso Furtado: a Brazilian social thinker
}

\author{
Rosa Maria Vieira $\star \star$
}

Resumo: Este artigo tem como objetivo analisar as concepções teóricas de Celso Furtado e discutir as acomodações que realiza entre teoria da Cepal e o moderno pensamento social brasileiro. Procura-se ressaltar a importância da multidisciplinaridade na sua formação intelectual, discutir suas concepções sobre os papeis do Estado e dos intelectuais no processo de desenvolvimento da periferia e, além disso, sublinhar seu status de pensador social no Brasil.

Palavras-chave: Celso Furtado Estado e Planejamento. Subdesenvolvimento. Intelligentsia. Pensamento social brasileiro.

Abstract: This article aims to analyze Celso Furtado's theoretical concepts and discuss the accommodations he makes between ECLAC's theory and modern Brazilian social thought. It aims to highlight the importance of multidisciplinarity on his intellectual formation, discuss his concepts about the roles of the state and of intellectuals in the development of lower income areas, and underscore his status as a social thinker in Brazil.

Keywords: Celso Furtado. State and planning. Underdevelopment. Intelligentsia. Brazilian social thought.

\footnotetext{
* Submissão: 16/11/2020 | Aprovação: 11/01/2021 | DOI: 10.29182/hehe.v24i1.788

$\star \star$ Professora do Departamento de Economia da PUC-SP e orientadora acadêmica na FGV-SP | E-mail: rosa.vieira@fgv.br | ORCID: 0000-0002-2823-0540
} 
“Sozinha, a Economia não vai a lugar nenhum". ${ }^{1}$

(Carlos Lessa)

Entre os economistas brasileiros, Celso Furtado é o que melhor expressa o espírito contido na provocação de Carlos Lessa. Seguramente, como o mais fecundo teórico da primeira geração da Comissão Econômica para a América Latina e o Caribe (Cepal), que fez da interdisciplinaridade um dos traços identitários de suas formulações intelectuais, Furtado ultrapassou em complexidade e amplitude analítica até mesmo as elaborações originais de Raúl Prebisch. Sua concepção de ciência econômica pode testemunhar o caráter fundante do diálogo interdisciplinar:

[...] a Economia não chegaria a ser para mim mais que um instrumental, que me permitia, com maior eficácia, tratar problemas que me vinham da observação da história ou da vida dos homens em sociedade. Pouca influência teve na conformação do meu espírito. Nunca pude compreender a existência de um problema estritamente econômico. (Furtado, 1983, p. 36)

Para Furtado, os processos econômicos eram "como cadeias de decisões e estas como estruturas de poder", afastados "dos conceitos de mecanismo e equilíbrio, que são a essência de todo enfoque neoclássico". Sem o recurso à história, à vida em sociedade, a economia seria, segundo ele, apenas uma “ciência menor, para gente sem imaginação". (Furtado, 1983, p. 36 e 40)

Dono de uma obra multifacetada de ressonância mundial, Celso Furtado foi o mais cosmopolita dos modernos pensadores sociais brasileiros. E essa referência como pensador social, não apenas como economista, leva em consideração a amplitude e a diversidade teórica de sua obra e o caráter múltiplo de suas intervenções nos embates políticos pelas reformas no Brasil, ao final da década de 1950 e início dos anos 1960.

As leituras da Sociologia do Conhecimento de Mannheim, o contato com a sociologia alemã de Max Weber, Tonnies, Hans Freyer, Simmel; os estudos sistemáticos de historiadores como Henry Pirenne, Sombart e Antonio Sérgio; a descoberta de Schumpeter e das teorias do desenvolvimento de François Perroux, para além das formulações cepalinas e keynesianas, prepararam-no para intervir na discussão e na atualização da "questão nacional” no Brasil, nos anos 1950 e início da década de 1960.

${ }^{1}$ Carlos Lessa, no documentário Um sonho intenso (2014), de José Mariani. 
Uma abordagem acurada de sua obra, que transcenda o trato das análises estritamente econômicas, põe em relevo seus vínculos com uma tradição do pensamento brasileiro que fez da "questão nacional" o grande desafio da intelligentsia que, no pós-1930, interpretou o país a partir de novos parâmetros intelectuais, tais como o culturalismo, o weberianismo, o marxismo, que superaram o racismo, o evolucionismo e o determinismo imperantes na produção teórica do final do século XIX e início do século XX. É a Francisco de Oliveira, aliás, que se deve a percepção inaugural e a referência a Furtado como o quarto "demiurgo intelectual" do Brasil moderno, figurando ao lado de Gilberto Freyre, Sérgio Buarque de Holanda e Caio Prado Jr.

Furtado transformou a preocupação da Cepal com o subdesenvolvimento da América Latina na investigação intelectual do modo particular como o capitalismo se reproduzia no Brasil. Segundo ele, essa realidade singular cobrava não apenas um corpo teórico específico para análise, como também um caminho próprio para seu desenvolvimento, sustentado pela industrialização, pela acumulação interna, e que não poderia ser trilhado nas condições de livre atuação das forças de mercado. Ao fazê-lo, Furtado releu as teses cepalinas, dando-lhes uma dimensão de historicidade que originalmente não tinham e, sobretudo, acomodando-as a um substrato teórico-ideológico de bases nacionais e de grande influência, representado pelo pensamento social brasileiro comprometido com projetos de modernização.

De um modo mais claro, Furtado, envolvido com a problemática da "construção nacional", traduziu essa edificação em termos da ultrapassagem do subdesenvolvimento, da negação radical de uma "vocação agrária” do país e do reconhecimento de um destino comum compartilhado com a América Latina. Como argamassa intelectual, ofereceu uma formulação teórica sustentada pelos procedimentos analíticos e pela linguagem científica de uma nova disciplina que, a partir de meados do século XX, passou a disputar espaço com as interpretações sociológicas, antropológicas e jurídicas da realidade brasileira, então imperantes. Ou seja, a Economia, que, como um campo específico do conhecimento, nasceu acompanhando a emergência da forma capitalista industrial de produzir mercadorias no Brasil.

Em continuidade a uma prática recorrente dos ideólogos da "construção nacional" no Brasil, Furtado levou a cabo uma das possibilidades ideológicas do oficio de historiador: buscar numa temporalidade remota as determinações profundas do projeto nacional, de modo a the conferir legalidade, procurando demonstrar sua realização como parte integrante dos anseios mais profundos 
do povo-nação. Seu livro mais influente, Formação econômica do Brasil, inscreve-se nessa tradição. Na tradição dos intelectuais brasileiros engajados que buscaram no passado, diligentemente perscrutado, a legitimidade histórica para suas propostas de construção da nacionalidade.

Formação econômica do Brasil, um vasto painel das transformações econômicas da colônia à industrialização substitutiva de importações, foi elaborado com o propósito de demonstrar as peculiaridades históricas da formação econômica de um país subdesenvolvido. E, subjacente à busca das raízes do atraso brasileiro, a intenção de demonstrar que subdesenvolvimento não era simplesmente um estágio natural do desenvolvimento econômico e que sua superação não poderia dispensar nem um esforço teórico original, nem uma programação racionalmente conduzida pelo Estado. O "tema das elites" e o "amor ao Estado", de larga tradição no pensamento social brasileiro, ressurgem na obra de Furtado, redimensionados em termos da ação racional de uma intelligentsia que, fazendo uso do planejamento e do Estado, promoveria a superação do subdesenvolvimento.

É sabido que no Brasil a "construção nacional”, desde suas origens, teve dimensões antiliberais e que, ao longo da história republicana, assumiu claras feições antidemocráticas, haja vista os períodos ditatoriais. Marcam a formação histórica brasileira as transições cruciais realizadas a partir de pactos entre as elites, com arranjos pelo alto, sem rupturas políticas efetivas e sempre excludentes com relação às massas. Define a edificação nacional a intervenção continuada do Estado, palco da intermediação de antigos e novos interesses de grupos dominantes, que se hipertrofiou continuamente, dando vida a um organismo agigantado, de caráter híbrido, representando, ao mesmo tempo, as forças de mudança e de conservação. Um espaço de conciliações contínuas, sem que nele os interesses populares tivessem verdadeira representação. Em suma, um Estado que não conseguiu se modernizar plenamente e nem se tornar efetivamente republicano, mantendo-se, no mais das vezes, a serviço do manuseio e dos interesses privados das classes dominantes.

Nesses termos, justifica-se a ideia de que, para se analisar o lugar do Estado e a atuação das elites na produção intelectual e no projeto de desenvolvimento de Furtado, é preciso levar em conta os ecos da longa duração dessas temáticas na tradição brasileira e na política institucional do país. A sugestão é a de que, ao seguir tal itinerário no processo analítico, será possível desvendar os contornos peculiares das formulações planificadoras de Celso Furtado e das suas concepções sobre o papel do Estado, que apenas as referências às 
raízes cepalino-keynesianas não propiciam. Em última instância, é por esse caminho que se poderá flagrar a potência da interdisciplinaridade na formação intelectual de Furtado.

\section{O lugar do Estado e do planejamento no projeto de desenvolvimento nacional}

Sabe-se que o Estado brasileiro assumiu funções essenciais no processo de acumulação capitalista no país. Essas relações se aprofundaram significativamente no pós-1930, tornando-se estratégicas para a reprodução do capital, particularmente nos setores que escapavam aos interesses e às possibilidades da burguesia agrária brasileira, ou do capital estrangeiro.

O Estado, centralizado e nacionalmente articulado, assumiu tarefas básicas: sustentou políticas econômicas de caráter industrial; tornou-se produtor de mercadorias e prestador de serviços, responsabilizou-se pela infraestrutura energética, pelos transportes, pelas indústrias de base; garantiu crédito industrial e avalizou empréstimos; fez da política cambial um instrumento de proteção de setores da indústria e de atração de investimentos. A ele coube, também, a responsabilidade de institucionalizar o mercado de força de trabalho, de que foi exemplo a legislação sindical e trabalhista.

Até meados do século passado, não houve, propriamente, planejamento econômico no Brasil, pois as inúmeras medidas econômicas, as reformas administrativas e a reestruturação do aparelho de Estado, para o desempenho das novas funções, não resultaram de estudos de caráter global e sistemático. Segundo Celso Lafer (1987, p. 29-30), até 1956, as tentativas de planejar a economia brasileira tinham sido mais propostas, mais diagnósticos, mais esforços no sentido de racionalizar o processo orçamentário; em suma, medidas mais puramente setoriais "do que experiências que pudessem ser enquadradas na noção de planejamento propriamente dito".

Planejamento econômico, propriamente, só a partir de Juscelino $\mathrm{Ku}-$ bitschek, com o Plano de Metas e com os projetos de desenvolvimento regional, nacionalmente articulados, como os da SUDENE. Foi nesse período que a trajetória de Furtado se confundiu com iniciativas de racionalização do trato da res publica no Brasil e com projetos de desenvolvimento levados a efeito até o Golpe Militar de 1964.

Afastando-se da Cepal no final dos anos 1950, onde durante uma década ocupou o cargo de Diretor da Divisão de Desenvolvimento, Furtado, 
no Brasil, envolveu-se em intensa atuação administrativo-estatal, que conciliou com sua produção teórica. Pouco antes, ainda como funcionário das Nações Unidas, havia chefiado o Grupo BNDE-Cepal, responsável pelo Estudo de um programa de desenvolvimento para o Brasil, base do Plano de Metas. Posteriormente, já como um dos diretores do BNDE, foi nomeado para o Grupo de trabalho para o desenvolvimento do Nordeste, responsabilizando-se por um estudo (Uma política de desenvolvimento econômico para o Nordeste) que orientou a atuação da SUDENE. Por fim, como primeiro titular do Ministério do Planejamento, criado pelo governo Goulart, deu forma ao Plano trienal de desenvolvimento econômico e social (1963-1965).

Nos documentos, nos livros e nas entrevistas dessa época, ${ }^{2}$ estão temas que, persistindo em combinações variadas, dão direção à produção teórica e sentido à atuação de Furtado como administrador público. Aí se encontram sua convicção reformadora; sua concepção de intelectual como um pensador acima das classes e como instrumento esclarecido do progresso, dotado de racionalidade científica e engajado na luta contra o atraso; sua crença na isenção científica, em que razão e ciência fazem parceria com a neutralidade, de certo sabor positivista. Percebe-se, também, seu empenho em demarcar diferenças entre as concepções estruturalistas e o campo teórico-econômico neoclássico, em sublinhar a importância da orientação multidisciplinar na formação do economista, em defender a intervenção planificadora e democrática do Estado para controle das forças cegas do mercado, de modo a colocá-las a serviço do desenvolvimento. Ou, sinteticamente, aí está a sua disposição para abrir caminho às reformas que levassem o Brasil à superação do subdesenvolvimento, através do manejo do pensamento econômico estruturalista e da planificação estatal.

Planejamento, democracia e racionalização são questões antigas.Acompanham Celso Furtado desde os tempos da formação inicial na Faculdade de Direito da Universidade do Brasil, onde, em lugar do conhecimento jurídico, inclinou-se para os estudos de administração pública.

Entre os tempos da Faculdade de Direito e o final da década de 1950, quando se envolveu diretamente na luta pelas reformas no Brasil, Furtado

\footnotetext{
2 São obras deste período: "O desenvolvimento econômico", Revista Econômica Brasileira, Rio de Janeiro, n. 1, 1955; Uma economia dependente, Rio de Janeiro: MEC, 1956; Perspectivas da economia brasileira, Rio de Janeiro: MEC/ISEB, 1958; Formação econômica do Brasil, Rio de Janeiro: Fundo de Cultura, 1959; Operação Nordeste, Rio de Janeiro: MEC/ISEB, 1959; Desenvolvimento e subdesenvolvimento, Rio de Janeiro: Fundo de Cultura, 1961; A pré-revolução brasileira, Rio de Janeiro, Fundo de Cultura, 1962; Dialética do desenvolvimento, Rio de Janeiro: Fundo de Cultura, 1964.
} 
doutorou-se em Economia Política, na França do pós-guerra, acompanhou o debate teórico sobre a regulação da ordem capitalista e, sobretudo, sofreu as influências do movimento que transformou o mundo periférico em objeto da análise econômica. Especificamente, isso ocorreu quando o segmento colonial pobre e atrasado, recém-incluído no rol dos Estados-Nação independentes, passou a cobrar políticas de desenvolvimento e a desafiar o pensamento econômico para uma teorização sobre as virtualidades e as mazelas do capitalismo na periferia.

Durante os anos de estudo na Sorbonne, além da tese sobre a produção açucareira no Nordeste brasileiro e nas Antilhas, do conhecimento sistemático das teorias econômicas clássicas, das leituras regulares de Marx e Keynes, da proximidade com história econômica, Furtado recebeu a influência decisiva de François Perroux, o mais importante economista francês da geração pós-guerra, na época em trânsito para o estruturalismo. Foi graças às suas concepções - em especial a teoria do "pólo de crescimento", segundo a qual o desenvolvimento econômico resultava de uma vontade política - que Furtado pôde sedimentar a ideia do Estado como fautor do dinamismo econômico, modificador das estruturas sociais.

Faltava, no entanto, a experiência decisiva para sua formação intelectual: o ingresso na Cepal, em 1948, como membro da equipe chefiada por Prebisch. Segundo Furtado, a Cepal foi sua escola de trabalho como economista. Ali pôde estudar a América Latina, dirigir missões econômicas no México, no Chile, na Argentina e, sobretudo, fazer análises comparativas. A Cepal permitiu-lhe enxergar o Brasil com outras lentes, reler a questão nacional na perspectiva de um destino histórico comum à América Latina e perscrutar a teoria de Keynes com nova abordagem. A partir daí, o atraso brasileiro passou a ser a questão-chave nas suas reflexões:

Onde estava sua inferioridade? Superada a teoria da inferioridade racial, a resposta só poderia estar na História, e lá fui buscá-la. Tudo isso me obrigou a repensar, a abrir um caminho. E comecei a ver o fim do túnel quando li Keynes. Não posso dizer que descobri Keynes na CEPAL, porque já o havia estudado antes. Mas, até então, eu via o Keynes da "teoria do ciclo econômico", que era a sua grande contribuição e levava à política de estabilização. $\mathrm{Na}$ CEPAL, comecei a perceber a importância da visão macroeconômica da História. Tratava-se, agora, de olhar a História, vendo o macroeconômico, para entender a lógica do atraso e descobrir os fatores que impediam o crescimento de um país como o Brasil. (Furtado apud Vieira, 2004, p. 31) 
Tendo em vista todo esse conjunto de referências, percebe-se que sem a compreensão do conceito cepalino de subdesenvolvimento como categoria mediadora essencial, conformadora da leitura teórica e das concepções reformistas de Furtado, pode-se incorrer no erro de deixar escapar o que élhe peculiar no tratamento do papel do Estado (keynesianamente pensado) e da ação racionalizadora dos seus quadros técnicos e intelectuais. Por isso, algumas questões demandam esclarecimento: em que consistia o planejamento nas nações subdesenvolvidas? Qual era o papel do arsenal keynesiano? Como projetar a atuação do Estado e de seus técnicos no Brasil?

Desde logo é preciso salientar a preocupação de Furtado em não transplantar para a periferia do capitalismo as experiências de planificação já existentes. A soviética, fundada na ideia de "balanços setoriais", herança das economias de guerra, estava, de antemão, descartada, seja porque "não conseguira progredir nem na direção da globalização (balanço nacional), nem na da previsão do comportamento da demanda de bens finais (balanços financeiros)", por obscuras razões cobertas de "retórica ideológica"; seja porque nessa economia o salário era determinado "administrativamente", deixando-se de lado a "motivação do trabalhador" e a "eficiência na coordenação de decisões". Já os países capitalistas de industrialização avançada que lançaram mão da intervenção do Estado para fazer frente às instabilidades cíclicas do capitalismo, aos efeitos ruinosos da Depressão de 1929, poderiam oferecer apenas referências, pois, no caso dessas nações, “o pleno emprego" era por si só "suficiente para assegurar um elevado nível de investimentos, vale dizer, de criação de novos empregos" (Furtado, 1985, p. 128-129).

Bem diferentes eram as condições do mundo periférico, de países como o Brasil, que conheceram um processo singular de industrialização por substituição de importações, espontânea e problemática, nos termos de Furtado. Essa peculiar transição da economia agroexportadora para a industrial se mostrou incapaz de romper com o dualismo estrutural, característico do subdesenvolvimento. A convivência entre os setores econômicos arcaicos e as novas áreas mais dinâmicas, as taxas insuficientes de acumulação de capital e os limites impostos pelo mercado interno cobraram alto preço ao processo de desenvolvimento, seja em termos de concentração de renda, de disparidades regionais, de dependência tecnológica e de endividamento externo; seja em termos da tendência à perda do dinamismo econômico, que abria caminho a longos períodos de estagnação, além da manutenção das altas taxas de desemprego estrutural da força de trabalho. 
No caso da periferia subdesenvolvida, não fazia sentido colocar como "objetivo da política econômica o pleno emprego da força de trabalho". O que, de fato, importava era conseguir o "progressivo aumento da produtividade média". Como o que caracterizava o subdesenvolvimento era, sobretudo, "o desperdício de mão-de-obra por causa da insuficiência de capital", a questão central passava a ser a otimização no uso do capital, fator de produção escasso "a partir dos constrangimentos criados pelo comércio exterior, pela taxa de poupança interna, pela entrada líquida de capital e pelas preferências da coletividade com respeito à composição da oferta de bens de consumo". No Brasil, a ação do Estado deveria se concentrar na promoção de mudanças estruturais e na definição dos espaços de atuação dos empresários privados, ainda que para tanto fosse necessário enfrentar a inoperância do aparelho de Estado e a falta de dinamismo da classe empresarial. No primeiro caso, o problema poderia ser resolvido por meio de "reforma administrativa e um grande esforço de aperfeiçoamento dos quadros do setor público"; quanto ao segundo, sem a possibilidade de equação imediata, havia que se correr "o risco de hipertrofia da ação empresarial estatal" (Furtado, 1985, p. 129 e 132).

Múltiplas questões envolviam esse conjunto. A começar pelo desafio de não se tomar por analogia as experiências dos países centrais, uma vez que o atraso da periferia não correspondia, simplesmente, a um estágio natural de evolução do capitalismo, a debilidades transitórias, antecedentes naturais da reprodução madura do capital. Segundo Furtado, o subdesenvolvimento era um fenômeno histórico moderno, "coetâneo do desenvolvimento, como um dos aspectos da propagação da revolução industrial”, decorrência do modo como se difundiu a "técnica moderna no processo de constituição de uma economia de escala mundial" (Furtado, 1968, p. 3-4). Pelo fato de serem contemporâneos das economias desenvolvidas, que lideraram a constituição do sistema internacional, os países subdesenvolvidos não podiam, simplesmente, repetir esse processo. Daí a necessidade de se tomar em consideração as peculiaridades da periferia, pois só assim seria possível descobrir até onde a experiência dos países desenvolvidos podia servir como referencial para os subdesenvolvidos, cujo progresso estava na dependência da capacidade de criar sua própria história.

Tendo em vista a particularidade do capitalismo periférico, o keynesianismo tinha que, necessariamente, ser aclimatado aos trópicos, pois a ação compensatória do Estado não poderia ser apenas conjuntural, ter tão-somente um 
caráter anticíclico. Se nos países centrais o propósito era a recondução do sistema econômico ao seu ponto de equilíbrio, ao pleno emprego e à otimização de uma poupança ociosa, no mundo subdesenvolvido se tratava de uma ação permanente do Estado, com propostas públicas voltadas à superação dos obstáculos estruturais que impediam a arrancada para o desenvolvimento. Daí a razão de Furtado mesclar categorias keynesianas com a busca do sentido da história econômica do Brasil e da América Latina, pensado em termos de "economia colonial" (base do estatuto periférico), o que resultava em formulações que não expressavam um keynesianismo puro, mas uma "derivação de análise macroeconômica de inspiração keynesiana”, nos termos de Ricardo Bielschowsky (2000, p. 135).

\section{A atuação de uma intelligentsia reformadora}

Destacados o papel decisivo do Estado na superação do subdesenvolvimento e o recurso a um keynesianismo aclimatado às condições da periferia, restam, ainda, algumas questões, diretamente ligadas à realidade nacional. Dispunha a sociedade brasileira de condições instrumentais para superar as dificuldades antepostas ao seu desenvolvimento? Suas classes dirigentes estavam à altura da empreitada? Quem seriam os agentes responsáveis pelas reformas?

Dialética do desenvolvimento, publicado em janeiro de 1964, foi o livro em que Furtado, mais claramente, respondeu a essas questões, revelando aspectos importantes da orientação ideológica e das concepções políticas que presidiam suas propostas de intervenção desenvolvimentista. Logo na introdução, um dado revelador da lógica que sustentava seu projeto: o papel dos intelectuais no processo de desenvolvimento, que, segundo ele, era o de esclarecer as consequências das ações dos homens de Estado, de prevenir atos que contrariassem interesses coletivos e, sobretudo, de imprimir racionalidade a um mundo em que o destino humano se transformou em "problema político" e que, por sua natureza, estava impregnado de "elementos irracionais". Cabia ao intelectual essa responsabilidade por ser o "único elemento dentro de uma sociedade que não somente pode, mas deve sobrepor-se aos condicionantes sociais mais imediatos do comportamento individual". Na vertente conceitual da intelligentsia de Mannheim, Furtado lembrava que essa capacidade de se sobrepor às determinações sociais era o que possibilitava a esta categoria se movimentar num plano mais elevado de racionalidade, enxergar mais longe 
do que permitiam "as lealdades de grupo e as vinculações de cultura" (Furtado, 1964, p. 9-10).

Convencido da neutralidade e do poder transformador da razão científica, do papel dos intelectuais, que pairavam acima das irracionalidades da política e dos embates de classe, mergulhou no esclarecimento das contradições e dos impasses políticos gerados pelo modo singular como ocorreu a industrialização no Brasil, voltando sua atenção para aspectos que, comumente, não estavam presentes em análises estritamente econômicas. Liberto do olhar de economista que via o Estado como um epifenômeno da economia, permitiu que aflorasse a dimensão ideológica que presidia suas concepções.

Segundo Furtado, as circunstâncias históricas da transição capitalista no país eram responsáveis por sua ordem burguesa peculiar. Referia-se ao fato de a industrialização ter ocorrido no momento de declínio do dinamismo das atividades agroexportadoras, sem que houvesse uma clara consciência da natureza desse processo. A desagregação da economia cafeeira provocou repercussões imediatas no plano político, abrindo caminho à renovação das elites dirigentes que, a partir desse momento, escapavam ao universo ideológico dos cafeicultores. O progressivo predomínio do setor industrial, porém, não foi resultado de conflito aberto, de clara contradição entre as novas elites e os grupos políticos preexistentes, pois a franca decadência da "economia colonial", nos albores da industrialização, fez com que os setores agrários abandonassem um posicionamento ideológico consistente, dedicando-se, a partir daí, ao que Furtado chamou de "um improvisado oportunismo político" (Celso Furtado, 1964, p. 111).

Sua intenção era mostrar que, no trânsito para a economia industrial, o Brasil não conheceu o "deslocamento de uma superestrutura arcaica, como consequência de um processo de desenvolvimento de novas forças produtivas, cujos interesses procurassem afirmação no plano político". Em outras palavras, sem rupturas revolucionárias, a crise que abriu caminho à industrialização não resultou de contradições entre novos setores em desenvolvimento e ideologias superadas, pois, no processo de substituição das importações, o declínio da base econômica agrária não ocorreu em virtude da "concorrência de novo sistema em formação". A decadência foi, antes, reflexo do enfraquecimento dos estímulos externos, pois o Brasil, como "economia colonial", era apenas "uma das ramificações do capitalismo mundial, cujos centros estavam na Europa e nos Estados Unidos" e suas crises não passavam de "simples adaptações às novas condições surgidas nos centros dinâmicos da economia capitalista" (Furtado, 1964, p. 112). 
Da acomodação entre industriais em ascensão e grupos agrários decadentes, que detinham os centros de decisão política nacional, resultaram as dificuldades de diferenciação ideológica entre os dois segmentos. No plano político, a indefinição da classe industrial impediu a emergência de novas lideranças, capazes de modernizar os marcos institucionais brasileiros, fazendo com que homens ligados às oligarquias tradicionalistas continuassem a controlar os centros de decisão no país.

Em síntese, segundo Furtado, o Brasil não conheceu uma revolução burguesa clássica, nos moldes da que presidiu o desenvolvimento do capitalismo na Europa. Aqui, a indústria apenas se estabeleceu como "subproduto do realismo na defesa dos interesses cafeicultores", como "decorrência da crise da economia colonial e da forma como esta continua a defender-se, e não um fator causante dessa crise" (Furtado, 1964, p. 113 e 129). Isso fez com que o país entrasse em fase de modificações estruturais com classes dirigentes que, no essencial, eram praticamente as mesmas de antes, sem consciência desse processo e incapazes de implementar uma política industrial definida.

Além da dimensão social conciliadora com os setores agrários tradicionais, Furtado salientou, também, o fato de a burguesia industrial brasileira ter enveredado pela via da concessão aos capitais estrangeiros. Essa associação, que do ponto de vista dos interesses empresariais imediatos talvez tivesse sido a solução mais racional, revelou-se perversa para o país, pois a indústria se desenvolveu em estreita dependência das divisas externas e em contradição com a capacidade decrescente do Brasil para importar. Os grupos internacionais se apropriaram de parte da poupança nacional, "a taxas negativas de juros", e a política cambial lhes permitiu que "reintroduzissem no país a uma taxa favorecida os lucros que aqui auferiam e remetiam para o exterior" (Furtado, 1964,p.132-133). Disso resultou ampla desnacionalização da economia, que levou ao estrangulamento externo, deixando às claras as contradições entre os interesses do desenvolvimento nacional e as empresas controladas por grupos estrangeiros.

É importante que se atente para os desdobramentos políticos desse processo sui generis de transição, deduzidos por Furtado. A burguesia industrial brasileira que emerge de sua análise é uma classe gestada em íntima conexão com uma economia de "caráter colonial" e que, historicamente, não se mostrou à altura de suas tarefas nacionais, econômicas ou políticas. Tratava-se de uma burguesia cuja peculiaridade somente as condições do atraso brasileiro podiam explicar: uma classe com dificuldades de diferenciação ideológica 
perante as elites agrárias; um grupo social disposto à conciliação com os setores latifundiários, mesmo os mais atrasados, em defesa da propriedade privada, especialmente nos momentos de maior tensão social; impossibilitada de apresentar um perfil empresarial; disposta a concessões a grupos externos e, por isso mesmo, incapaz de levar à frente um projeto de desenvolvimento nacional.

Do mesmo modo como a peculiaridade histórico-estrutural de país subdesenvolvido esculpiu as feições da burguesia brasileira, também diferenciou sua classe trabalhadora. Segundo Furtado, o desenvolvimento na periferia, ocorrido pela absorção de fatores de produção da economia arcaica preexistente e pela utilização de tecnologia transplantada das áreas centrais, permitiu que os capitalistas ficassem numa situação privilegiada em relação aos trabalhadores, em razão da grande oferta de mão de obra (remanescente da agricultura arcaica) que a tecnologia industrial importada (poupadora mão de obra) não absorveu, gerando uma situação tendente a inibir o processo de luta de classes. Como decorrência, os capitalistas se acomodaram, revelando pouco dinamismo e acostumados a elevadas taxas de lucro, que não eram postas em xeque por pressão das massas assalariadas.

Essas massas eram compostas por trabalhadores urbanos, empregados no setor terciário; por subempregados que viviam nas grandes cidades, expulsos pela miséria do campo, ocasionalmente absorvidos em obras públicas e construção civil; por camponeses dispersos, submetidos aos latifundiários, incapazes de desenvolver um movimento político autônomo; por operários industriais, que compunham um agrupamento homogêneo, porém numericamente inexpressivo. Estes, ao contrário do proletariado dos países centrais, tinham dificuldades de desenvolver consciência de classe, pois, principalmente, a primeira geração não conseguia perceber suas condições como resultado de um processo de degradação social, como ocorria com os artesãos europeus durante a Revolução Industrial. Ao contrário, oriundos em sua maioria de Minas Gerais e do Nordeste, de condições muito semelhantes às de "um servo rural", os operários percebiam-se como um grupo em ascensão social.

São evidentes as conclusões a que conduzem essas análises. Se no Brasil as instituições políticas clássicas (como o Legislativo), enredadas por processos conciliatórios entre antigos e novos grupos dominantes, mostravam-se inoperantes em face da modernização capitalista; se faltavam espírito empreendedor e liderança política aos industriais, cujos limites de consciência 
os inabilitavam para um projeto coerente de desenvolvimento autônomo, algo deveria tomar seu lugar na condução das reformas que eliminassem os desequilíbrios estruturais do país.

Nas formulações de Furtado, um poder ex-machina, fora dos arranjos convencionais das classes dominantes, deveria imprimir racionalidade ao espaço político e implementar o desenvolvimento no país. Esse poder, único capaz de condicionar modos racionais de atuação e engendrar uma política industrial consistente, assumia a forma de um Estado intervencionista, manejado por uma elite intelectual que, em razão do conhecimento científico, da neutralidade com que usava o instrumental técnico e do lugar especial que ocupava na sociedade (acima dos condicionantes sociais imediatos), estaria em condições de viabilizar um projeto de reformas, dando feição aos interesses nacionais e respondendo com eficácia às aspirações da coletividade.

A partir dessas formulações, pode-se inferir que, para Furtado, o jogo puramente parlamentar, nos moldes liberais clássicos, não tinha condições de responder com eficácia às demandas do processo de transformação capitalista no Brasil, mostrando-se incapaz de fazer frente às contradições do subdesenvolvimento. Em princípio, a reforma do Estado era apresentada como solução para a crescente falta de legitimidade política da classe dirigente e para a necessidade de adequarem as instituições aos imperativos da nova ordem industrial. Os agentes responsáveis pela "definição das aspirações coletivas", pelo "trabalho crítico de ação renovadora", que fariam o sistema funcionar, imprimindo eficácia ao Estado, não eram as tradicionais lideranças, ou representantes da burguesia industrial. Isso ficaria a cargo dos membros da "classe dos trabalhadores intelectuais", extrato em condições de "interpretar os valores em todos os campos da cultura" e "identificar aquelas aspirações que traduzem as tendências mais profundas do sentir social" (Furtado, 1964, p. 49). Furtado se referia aos economistas e aos administradores públicos versados no planejamento democrático.

\section{Considerações finais}

Sob a injunção das celeradas mudanças capitalistas no Brasil, na metade do século XX, Celso Furtado se rendeu ao fascínio da questão nacional, assumindo o desafio de um projeto em termos de "desenvolvimento para dentro". A exemplo dos ideólogos da nacionalidade que o antecederam, preocupou-se em identificar as peculiaridades do país, sob a mediação da concepção 
de subdesenvolvimento. Dentre as peculiaridades, ressaltou: ausência de uma burguesia nacional forte e inovadora, vocacionada para o comando de rupturas estruturais; continuidade da vida política manobrada por velhas oligarquias, no âmbito do liberalismo formal; inexistência das lutas de classes nos moldes dos países centrais, que barrava o florescimento de formas clássicas de organização política. Eram essas as singularidades que justificavam suas propostas de intervenção estatal, para muito além das práticas anticíclicas keynesianas.

Para o Estado reservava o papel de demiurgo da nação (soberana e desenvolvida), a exemplo do que, antes dele, fizeram outros ideólogos brasileiros compromissados com a modernização. Para a intelligentsia, cientificamente treinada no manejo das técnicas planificadoras, destinava as funções de imprimir racionalidade aos movimentos da política e substituir capitalistas destituídos de vocação para o comando do desenvolvimento nacional.

A mística do plano - a crença nas possibilidades quase ilimitadas do planejamento e da ação racionalizadora das elites superarem os limites do ordenamento social adverso, as fragilidades da acumulação e as contradições sociais - deu ao projeto de Furtado um inequívoco caráter utópico e voluntarista, que os movimentos da realidade encarregaram-se de desvelar. Suas análises, capazes de identificar a crise no processo de substituição de importações, a dimensão histórica do subdesenvolvimento, a impossibilidade da burguesia brasileira levar à frente um projeto de capitalismo autônomo e o caráter passivo das experiências nacionais de "revoluções pelo alto", no entanto, não lhe possibilitaram entender, de imediato, a nova etapa da acumulação capitalista, aberta com o Golpe Militar. No exílio (1966), analisando os primeiros movimentos da política econômica da ditadura, prognosticou a "pastorização" do país e uma longa estagnação, exatamente no momento em que o capital monopolista internacional transformava o Brasil num de seus espaços de reprodução e preparava o "Milagre Brasileiro".

Os novos tempos desmentiram os prognósticos de regressão econômica. A ditadura comprovou que era suficiente uma reconcentração de poder e de renda para que a economia perversamente se expandisse $\mathrm{O}$ novo modelo de desenvolvimento não demandava mudanças na estrutura produtiva, bastando-lhe o aprofundamento e a diversificação do consumo das classes médias e dos detentores de altas rendas.

No plano teórico, a cidadela das teses nacionalista de Furtado foi atingida por novas interpretações sobre os rumos do desenvolvimento capitalista 
na América Latina. Ganharam força análises que desvinculavam a industrialização ampliada da emancipação nacional. $\mathrm{O}$ desenvolvimento dependente e associado era apontado como o "desenvolvimento possível" para a periferia. Isto é, a ideia de que a acumulação industrial oligopolista poderia avançar, apesar da dependência de capitais estrangeiros e exclusão de parcelas significativas da população. Segundo os "dependentistas", os investimentos estrangeiros não seriam obstáculos, mas alavancas para os países periféricos.

A história reservou um lugar de honra no pensamento brasileiro às formulações de Celso Furtado. Sua pauta de resistência teórico-oposicionista aos efeitos socialmente perversos do capitalismo excludente no país, ainda hoje serve como referência para alguns, para os que se identificam com suas aspirações de reforma e inclusão econômica e social.

\section{Referências}

BIELSCHOWSKY, R. Pensamento econômico brasileiro. $4^{\mathrm{a}}$ ed. Rio de Janeiro: Contraponto, 2000.

FURTADO, C. M. Auto-retrato intelectual. In: OLIVEIRA, Francisco de (Org.). Celso Furtado. São Paulo: Ática, p. 30-41, 1983.

FURTADO, C. M. Formação econômica do Brasil [1959]. 34ª ed. São Paulo: Companhia das Letras, 2007.

FURTADO, C. M. Dialética do desenvolvimento. Rio de Janeiro: Fundo de Cultura, 1964.

FURTADO, C. M. Subdesenvolvimento e estagnação na América Latina. Rio de Janeiro: Civilização Brasileira, 1968.

FURTADO, C. M. A fantasia organizada. Rio de Janeiro: Paz e Terra, 1985.

LAFER, C. O planejamento no Brasil: observações sobre o Plano de Metas (1956-1961). In: LAFER, Betty Mindlin. Planejamento no Brasil. São Paulo: Perspectiva, p. 29-50, 1987.

OLIVEIRA, F. de. A navegação venturosa. In: OLIVEIRA, Francisco de (Org.). Celso Furtado. São Paulo: Ática, p. 7-27, 1983. 
VIEIRA, R. M. Celso Furtado: reforma, política e ideologia (1950-1964). $2^{\mathrm{a}}$ ed. São Paulo: Editora UFABC, 2020.

VIEIRA, R. M. Entrevista com Celso Furtado. Revista de História Oral, n. 7, p. 21-40, jun. 2004. 